\title{
RITMO DE ATIVIDADE DE LIOLAEMUS OCCIPITALIS BOULENGER (SAURIA, TROPIDURIDAE) NA PRAIA DE QUINTÃO, RIO GRANDE DO SUL, BRASIL
}

\author{
Laura Verrastro ${ }^{1}$ \\ Clóvis Souza Bujes ${ }^{1}$
}

\begin{abstract}
RHYTHM OF ACTIVITY OF LIOL.AEMUS OCCIPITALIS (SAURIA, TROPIDURIDAE) AT THE QUINTÃO BEACH, RıO GRANDE DO SUL, BRAZIL. The activity rhythm of the lizard Liolaemus occipitalis Boulenger, 1885 was studied during the summer of 93 at the sand dunes of the Quintão beach, from 06:00-18:00h. During sunny days this lizard exhibited two peaks of activity (1000-1200h and 1400-1600h), and in the cloudy days it exhibited one peak of activity (1200-1400h). The number of burrows was observed and the different soil temperatures was compared with the rhythm of activity exhibited by the lizards. Rhythm of activity is determined mainly by soil surface temperatures. KEY WORDS. Tropiduridae, Liolaemus occipitalis, activity, neotropical lizards, sand dunes
\end{abstract}

Liolaemus Wiegmann, 1883 apresenta-se bastante diversificado com mais de 120 espécies (DonOSO-BARRos 1966), distribuído entre os paralelos $25^{\circ}$ e $55^{\circ}$ da América do Sul.

No Brasil, o gênero possui três espécies: L. lutzae Mertens, 1938, restrita às restingas do Rio de Janeiro (RocHA 1988); L. occipitalis Boulenger, 1885, encontrada nas dunas costeiras do estado do Rio Grande do Sul e sul de Santa Catarina; e L. wiegmanni (Dum. \& Bib., 1837), restrita às restingas da Laguna dos Patos, no Rio Grande do Sul (Peters \& Donoso-Barros 1970).

No Rio Grande do Sul, L. occipitalis é abundantemente encontrado nas costas arenosas desde Chuí até Torres (Fig. 1). Este lagarto caracteriza-se por possuir um padrão de coloração críptico que o confunde com a areia. Apresenta um comprimento rostro-anal médio de $60,2 \mathrm{~mm}$ para machos e $53,2 \mathrm{~mm}$ para fêmeas. A reprodução ocorre de setembro a março (VERRASTRO \& KRAUSE 1994). Tem como comportamento termorregulador alternar-se entre locais expostos ao sol e à sombra. Costuma enterrar-se superficialmente na areia ou construir tocas.

A temperatura nos répteis é regulada através de mecanismos fisiológicos e comportamentais. Este último mecanismo inclui orientação e posição corpórea em períodos de exposição ao sol ou à sombra. Muitos lagartos são capazes de manter uma temperatura corpórea constante durante o dia, desde que se refugiem quando tal temperatura se aproxima dos extremos de tolerância (SIMONETTI 1984).

O objetivo deste trabalho é o estudo do ritmo de atividade de L. occipitalis ao longo do dia, no verão de 1993.

1) Departamento de Zoologia, Instituto de Biociências, Universidade Federal do Rio Grande do Sul. 90046-900 Porto Alegre, Rio Grande do Sul, Brasil.

E-mail: lauraver@vortex.ufrgs.br ou csbujes@conex.com.br 


\section{MATERIAL E MÉTODOS}

\section{Descrição da área}

O presente estudo foi realizado na praia de Quintão, localizada a $120 \mathrm{~km}$ de Porto Alegre, Município de Palmares do Sul, Rio Grande do Sul (30²4’S e $\left.50^{\circ} 17^{\prime} \mathrm{W}\right)$. A área escolhida dista $4 \mathrm{~km}$ da Lagoa do Quintão e $3 \mathrm{~km}$ do oceano, e constitui-se em uma planície de dunas móveis em terreno holocênico, incluído na planície arenosa litorânea (DELANEY 1965).

O solo é de depósitos sedimentares arenosos quartzosos, não fixados, de acumulação eólica de origem quaternária (PORTO \& CORTAZZI 1982).

O clima no sistema de Köppen é do tipo Cfa, onde a precipitação média anual situa-se em torno de $1323 \mathrm{~mm}$, sem existir uma estação seca característica. A temperatura média anual é de $20^{\circ} \mathrm{C}$. Os ventos predominantes são de origem nordeste, em quase todo o ano (HASENACK et al. 1987)

As formações vegetais do litoral foram descritas em sua maior parte por Pfadenhauer \& Ramos (1979); Pfadenhauer (1980) e Waechter (1985, 1990).

A vegetação na área de estudo é, normalmente, escassa, com cobertura vegetal não superior a 5\%, formada exclusivamente por plantas herbáceas, psamófilas, predominantemente da família Gramineae. Apresenta elevações constituídas por montículos de areia de $20-50 \mathrm{~cm}$, muitos deles junto a touceiras de vegetação herbácea. Nas depressões, ocorrem alagamentos temporários devido às chuvas torrenciais. Quando estas depressões acumulam matéria orgânica por mais, tempo podem ficar cobertas de vegetação densa e duradoura. Ali, verifica-se a presença de espécies como Juncus cf. maritimusLinn., formando densas touceiras em forma esparsa, e onde acumula-se maior quantidade de matéria orgânica, ocorre Lycopodium alopecuroides Linn. (Pterydophyta), Drosera cf. brevifolia Pursh. (Droseraceae) e Urticularia spp. (Urticulariaceae).

A espécie mais abundante é Panicum racemosum Lam., a qual forma agregados quase homogêneos em grandes extensões no topo dos montículos. Nos montículos mais baixos, ocorrem outras gramíneas, como Panicum sabularum Hack., Andropogon arenarium, Spartina cf. ciliata Brong.. Associadas as mesmas, encontra-se também a erva-capitão, Hydrocotyle umbellata Linn. (Umbelliferae) e Senecio crassifolius Linn. (Compositae).

\section{Metodologia}

Dentro da área de estudo, delimitou-se uma subárea de 450 por 200 metros na qual foram registradas as observações. O estudo desenvolveu-se nos períodos de 25 a 30 de janeiro e 15 a 20 de fevereiro de 1993. As visitas à área eram realizadas diariamente, abrangendo todos os períodos do dia, entre 6:00 e 18:00h. A área era percorrida a cada hora na sua totalidade, registrando-se em ficha de campo os indivíduos observados em cada horário e seu padrão de atividade no momento da observação. Devido às condições meteorológicas, não foi possível obter registros nos dias ensolarados, das 16:00h às 18:00h, e nos dias nublados, das 14:00h às 16:00h. Os resultados obtidos foram agrupados em freqüência de avistamentos e padrão de atividade em dias ensolarados e dias nublados. Os padrões de comporta- 


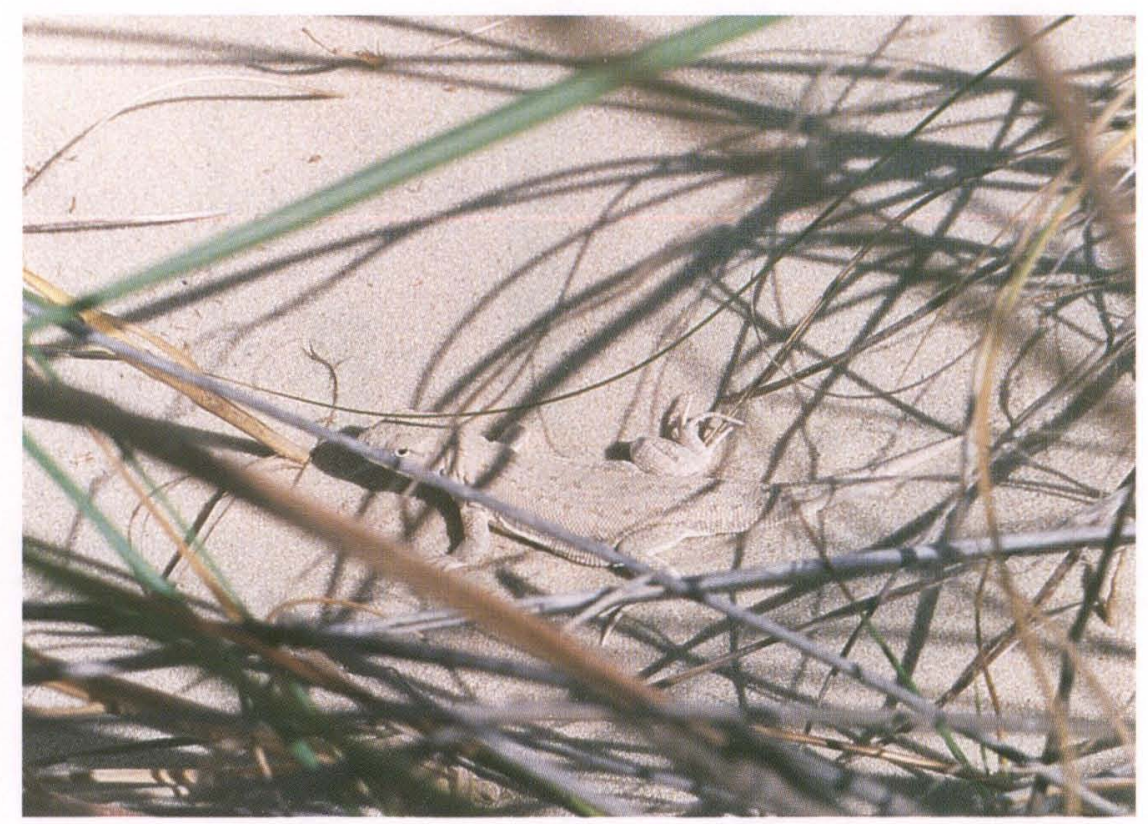

Fig. 1. Liolaemus occipitalis em seu ambiente característico, destacando-se sua condição criptica.

mento foram adaptados de RocHA (1988), e neste trabalho considerados como: "parado sob vegetação", "parado ao sol", "em deslocamento" e "parcialmente enterrado". Paralelamente, foram registradas as temperaturas do ambiente, da superfície do substrato e, do substrato em diferentes profundidades $(5,10,15,20$ $\mathrm{cm})$. Cada toca encontrada era marcada, medida e registrada sua temperatura. Os dados meteorológicos foram obtidos junto ao Departamento Estadual de Portos, Rios, Estuários e Canais (DEPREC) e Estação de Imbé (Rio Grande do Sul), a aproximadamente $20 \mathrm{~km}$ da área de estudo (Fig. 2).

\section{RESULTADOS}

Liolaemus occipitalis mostrou ser um lagarto exclusivamente diurno, com períodos de atividades entre 6:00 e 18:00h, estando sua freqüência associada às variações na temperatura diária.

Nos dias ensolarados, observou-se uma tendência ao padrão bimodal, com picos de atividade entre 10:00 e 12:00h, e entre 14:00 e 16:00h, quando registrou-se temperatura média do substrato de $34,7^{\circ} \mathrm{C}$ e $38,2^{\circ} \mathrm{C}$ respectivamente. $\mathrm{O}$ maior número de indivíduos foi avistado no último pico. Nos períodos mais quentes do dia (12:00-14:00h), a atividade era gradualmente reduzida (temperatura média do substrato de $38,5^{\circ} \mathrm{C}$ ) (Fig. 3A).

Em dias nublados, observou-se maior atividade no período compreendido entre 12:00 e 14:00h (temperatura média do substrato de $40,6^{\circ} \mathrm{C}$ ), tendendo o ritmo de atividade a um padrão unimodal (Fig. 3B).

Revta bras. Zool. 15 (4): 913 - 920, 1998 


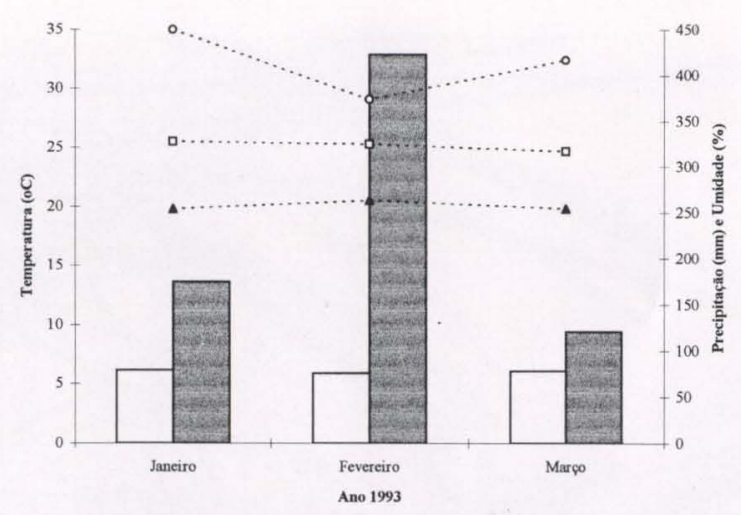

Fig. 2. Dados climáticos da região de Tramandaí-Cidreira nos meses de janeiro, fevereiro e março de 1993. Precipitação: barras escuras, umidade relativa: barras claras, temperaturas do ar: mínima (triângulos), média (quadrados) e máxima (círculos). Fonte: DEPREC.
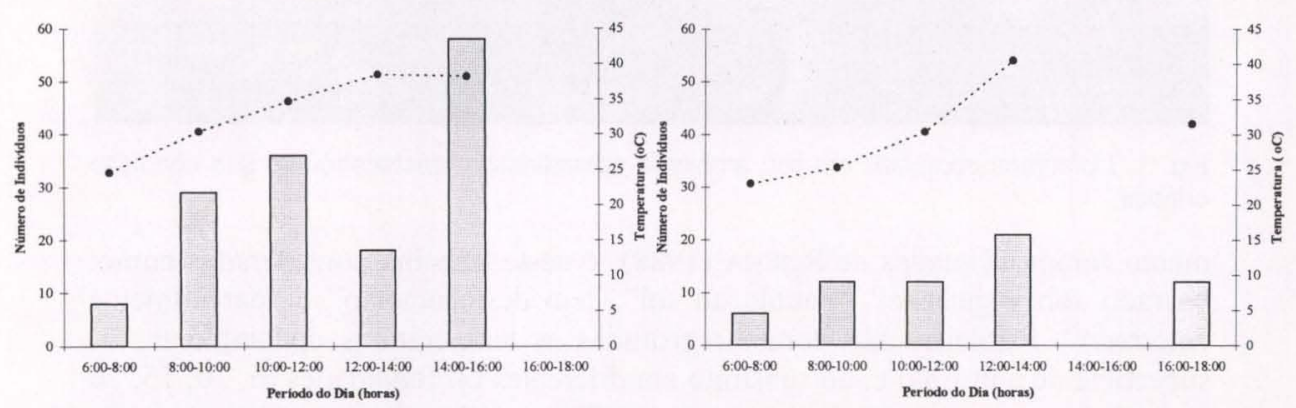

Fig. 3. Número de individuos de L. occipitalis avistados nas diferentes horas do dia, relacionados às respectivas temperaturas da superfície do substrato. (A) Em dias ensolarados, $(B)$ em dias nublados.

O período total de atividade dos lagartos foi de 600 minutos, em dias com sol, e de 840 minutos, em dias nublados.

O comportamento registrado com maior freqüência foi "parado sob vegetação" (Fig. 4A, B), principalmente nos períodos de maior atividade. Por outro lado, nas horas menos quentes do dia, a relação "parado sob vegetação"/"parado ao sol" diminuíu. Nas primeiras horas do dia (6:00h-8:00h), a atividade mais freqüente foi "parado ao sol".

Os lagartos constróem tocas cuja profundidade varia de 200 a $300 \mathrm{~mm}$. A abertura das tocas é semicircular e seu diâmetro não é maiores que $30 \mathrm{~mm}$. Geralmente, tais tocas são construídas junto à montículos de areia fixados por moitas de vegetação; tocas construídas em áreas muito próximas às planícies úmidas são pouco freqüentes. Pode-se observar que a temperatura do interior da tocas variou menos que a do substrato (Fig. 5), mantendo-se entre $26^{\circ} \mathrm{C}$ e $33^{\circ} \mathrm{C}$ ao longo do dia, enquanto a temperatura da superfície variou entre $25^{\circ} \mathrm{C}$ e $45^{\circ} \mathrm{C}$. No momento da fuga os animais procuram esconder-se na toca mais próxima. 
A

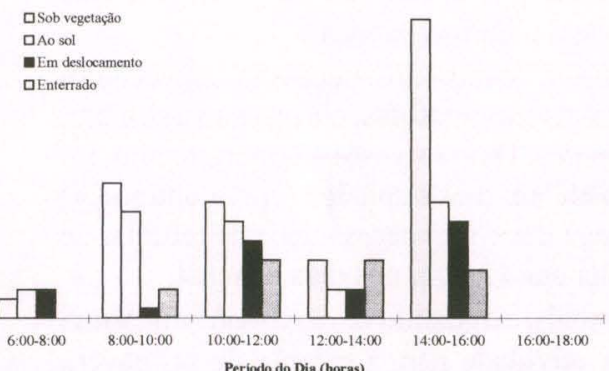

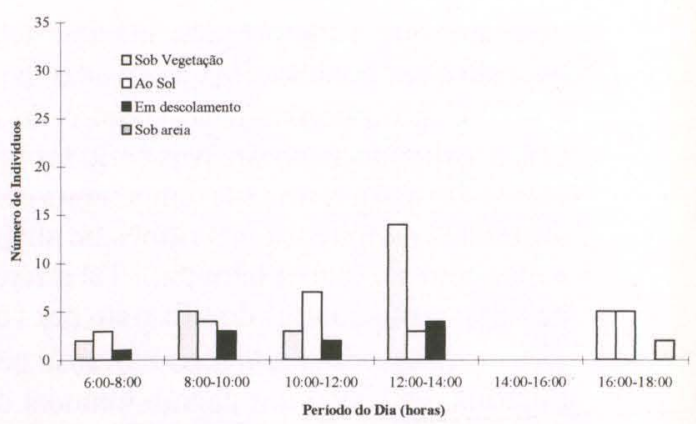

Fig. 4. Número de indivíduos de $L$. occipitalis avistado e tipo de atividade desenvolvida. (A) Em dias ensolarados, $(B)$ em dias nublados.

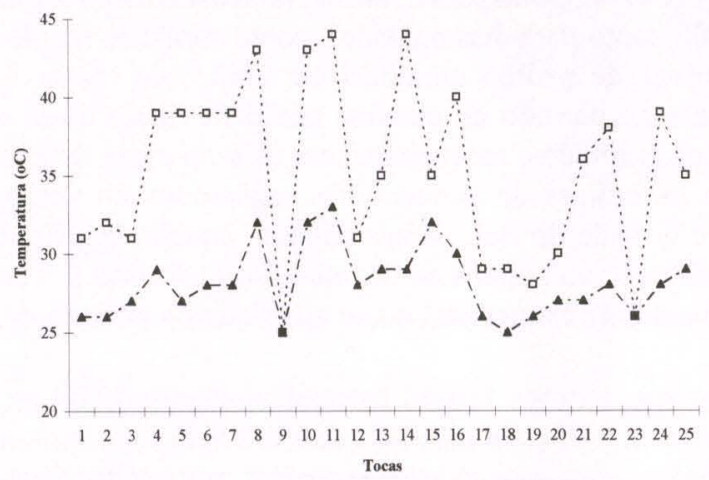

Fig. 5. Comparação entre as temperaturas nas tocas (triângulos) e na superfície do solo (quadrados).

Outra estratégia de fuga, observada neste estudo, foi enterrar-se na areia superficial. Para tal, utilizam a cabeça e as patas dianteiras em movimentos rápidos e alternados de escavação. Imediatamente, o lagarto acomoda seu corpo em forma de $\mathbf{S}$ e termina de cobri-lo com areia utilizando as patas traseiras. Finalmente, as patas são colocadas ao lado do corpo e a cauda é recolhida lateralmente. A procura de vegetação espessa entre as moitas e posteriormente o ato de enterrar-se é, ainda, outra forma eficiente de escape.

\section{DISCUSSÃO}

A partir dos resultados obtidos nas dunas da Praia de Quintão, verificou-se que $L$. occipitalis é um lagarto heliófilo, isto é, tem a radiação solar como um dos fatores determinantes do seu ritmo de atividade.

PIANKA (1969) comenta que, devido às temperaturas do ar e do substrato serem fortemente dependentes do tempo, a atividade temporal de um lagarto deve ser estritamente encaixada no seu requerimento termorregulatório. GUIBÉ (1970) 
verificou que a temperatura máxima tolerada por L. multiformis é $37^{\circ} \mathrm{C}$, e que exposto a temperaturas mais elevadas, procura o abrigo da toca.

Como observado no começo do dia, L. occipitalis necessita aquecer seu corpo, expondo-se ao sol. Nos períodos de altas temperaturas, ele procura a sombra, regulando desta forma sua temperatura corpórea. Devido a esse comportamento, foi observada a diferença nos ritmos de atividade em dias nublados (curva unimodal) e dias com sol (curva bimodal). Tal diferença deve-se à necessidade de refugiar-se das altas temperaturas do substrato por volta das 12:00h, nos dias com sol.

Alessandra Faria (comunicação pessoal), estudando L. occipitalis em Santa Catarina, verificou um padrão bimodal de atividade para a estação de primavera (estação mais quente estudada pela autora); com um pico entre 8:00 e 12:00h e outro entre 14:00 e 16:00h. Nas estações mais frias (outono e inverno), observou padrão unimodal, com pico de atividade entre 10:00 e 14:00h.

RochA (1988) registrou para L. lutzae, no Rio de Janeiro, picos de atividade entre 8:00 e 9:00h, tanto para dias nublados, como para dias ensolarados de verão, apresentando curvas de padrão unimodal em ambos os casos. As disparidades observadas quanto ao período de máxima atividade diária de $L$. occipitalis e $L$. lutzae, podem ser atribuídas, essencialmente, às diferenças de latitude. Por mais altos que sejam os índices de temperaturas registrados no verão, neste tipo de ambiente no Rio Grande do Sul, jamais atingem àqueles registrados por RocHA (1988), principalmente na superfície do solo. Desta forma, L. occipitalis parece emergir mais lentamente e apresenta maior atividade no período da tarde, nos dias ensolarados.

Paralelamente, RocHA (1988) calculou um período de atividade para $L$. lutzae de 406 $\pm 90,6$ minutos em dias nublados e 296 $\pm 150,6$ minutos em dias com sol, períodos inferiores aos aqui observados para L. occipitalis. Segundo este autor, isto está relacionado com o tipo de alimentação dos lagartos; L. lutzae apresenta dieta omnívora (ROCHA 1988), enquanto L. occipitalis, apresenta alimentação insetívora (VERRASTRO \& KRAUSE 1994). ROCHA (1988) sugere que a busca de artrópodos exige mais tempo de atividade que a procura de vegetais.

Quanto às atividades diárias, tanto em dias ensolarados, como em dias nublados, as que apresentaram maiores freqüências de observação foram "parado sob vegetação" e "parado ao sol" (Fig. 4A, B). É importante considerar que este lagarto apresenta uma estratégia alimentar do tipo "senta-e-espera" (VERRASTRO \& KRAUSE 1994), sendo muito comum observá-lo alimentado-se junto à vegetação onde existe grande abundância de insetos. Em populações de L. nigromaculatus, nas dunas costeiras do Chile Central, SimONETTI (1984) verificou que nas primeiras horas do dia os lagartos eram encontrados na areia, na periferia dos arbustos, enquanto nas horas mais quentes enterravam-se no centro dos arbustos, resolvendo sua situação de termorregulação e escape através de seleção de refúgios.

A seleção de refúgios por L. occipitalis também ocorre. De maneira similar ao verificado por BOGERT (1959), acerca do comportamento termorregulador nos lagartos, L. occipitalis também apresenta mudanças de postura em relação à incidência dos raios solares, por vezes deslocando-se para diferentes tipos de substrato, de acordo com as variações na temperatura ambiente. Esta espécie apresenta um 
padrão preferencial de atividade de termorregulação no início do dia. Para aquecer seus corpos, ficam expostos ao sol e nos períodos de temperaturas mais elevadas (acima de $38^{\circ} \mathrm{C}$, temperatura do substrato), procuram as sombras, evitando assim o superaquecimento.

Da mesma forma, pode-se observar este tipo de comportamento termorregulador em relação às temperaturas das tocas e da superfície. Desta maneira, evidencia-se a importância destes refúgios para a espécie como forma de manutenção de um microclima. Em alguns períodos, nos dias de verão, as temperaturas do substrato podem superar $45^{\circ} \mathrm{C}$, o que seria letal aos animais.

\section{CONCLUSÃO}

O ritmo de atividade de $L$. occipitalis é determinado diretamente pelas diferentes temperaturas do substrato. Suas atividades são exclusivamente diurnas e estão intimamente associadas à termorregulação. O hábito de construir e se abrigar em tocas é comum a esta espécie, que as utiliza para diversos fins, entre eles, a termorregulação.

AGRADECIMENTOS. Agradecemos ao Departamento de Zoologia da Universidade Federal do Rio Grande do Sul e a FAPERGS, pelo apoio dado através de Bolsa de Recém-Mestre e Auxílio a Pesquisa, processo ${ }^{\circ} 93.1131 .8$.

\section{REFERÊNCIAS BIBLIOGRÁFICAS}

BORGERT, C.M. 1959. How reptiles regulate their body temperature. Scientific Amer. 200: 415-420.

DELANEY, P.J.V. 1965. Fisiografia e geologia da superfície da planície costeira do Rio Grande do Sul. Publ. Esp. Esc. Geol. UFRGS, Porto Alegre. 6: 1-105. Donoso-Barros, R. 1966. Reptiles de Chile. Santiago, Univ. Chile, 458p. GuIBÉ, J. 1970. Données ecologiques -Cycles d'activité et hivernage, p.1396-1398. In: P.P. GRASsÉ (Ed.). Traité de Zoologie XIV, Anatomic, Systematique, Biologie. Paris, Masson et Cie., 1428p.

Hasenack, H.; W.L. FerRaro \& N.A. KaerCher. 1987. Relatório Final-Mapa

Climatológico. Porto Alegre, UFRGS-Centro de Ecologia, Laboratório de Climatologia, $18 \mathrm{p}$.

Peter, J. \& R. Donoso-Barros. 1970. Catalogue of the Neotropical Squamata. Part.I Lizard and Amphisbaenians. Bull. U.S. Nat. Mus. 297: 1-293.

Pfadenhauer, J. 1980. Die Vegetation der Küstendünen von Rio Grande do Sul Südbrasilien. Phytocoenologia. 8 (3/4): 321-364.

PFADENHAUER, J. \& F.R. RAMOS. 1979. Um complexo de vegetação entre dunas e pântanos próximo a Tramandaí. Rio Grande do Sul, Brasil. Iheringia., Sér. Bot., 25: $17-26$.

PIANKA, E.R. 1969. Sympatry of Desert Lizard (Ctenotus) in Western Australia. Ecology. 50 (6): 1013-1030.

Porto, R.P. \& A.M. Cortazzi. 1982. Carta de solos do Rio Grande do Sul. Mapas temáticos do Rio Grande do Sul. Porto Alegre, Secretaria de Agricul- 
tura, $21 \mathrm{p}$.

RocHA, C.F.D. 1988. Ritmo de atividade e microclimatologia do habitat de Liolaemus lutzae (Sauria-Iguanidae). An. Sem. Reg. Ecol., Rio de Janeiro, 6: 269281.

SiMONETTI, J. 1984. Refuge utilization by Liolaemus nigromaculatus a compromise between predation risks and thermoregulatory requeirment. Stud. Neotrop. Fauna Environ. 19 (1): 47-51.

Verrastro, L. \& L. Krause. 1994. Analysis of Growth in a Population of Liolaemus occipitalis Boul. 1885, from the Coastal Sand-dunes of Tramandai, RS, Brazil (Reptilia, Tropiduridae). Studies Neotrop. Fauna Environ. 29 (2): 99-111.

WAECHTER, J.L. 1985. Aspectos ecológicos da vegetação de restinga no Rio Grande do Sul, Brasil. Comun. Mus. Ci. PUCRS, Sér. Bot., Porto Alegre, 33: 49-68.

- 1990. Comunidades vegetais das Restingas do Rio Grande do Sul. Aciesp, São Paulo, 3: 228-248.

Recebido em 15.V.1997; aceito em 03.XI.1998. 